circumstances. Mr. Cadge says : " Robert Liston was the first surgeon in this country to use ether, and those who were present at University College Hospital on December 2 1st, 1846 and witnessed the complete and perfect success of that first venture, will not easily forget the dramatic character of that scene. I was present and assisted at the operation-amputation of the thigh by the double flap method. Someone present timed the operation; it took 30 seconds; the few arteries were tied, and all signs of blood cleared away. A towel was then thrown over the stump, and we watched anxiously for the patient to show that he was not dead; he presently woke up, and when asked once or twice if he could stand the pain of the operation, he accused us of cruelly trifling with his feelings, and when the towel was removed and he saw the naked stump, he burst into tears, and I thought Liston would do the same."

Many fresh fields of inquiry and separate study have been instituted. In 183I Alfred Swaine Taylor, the famous chemist and medical jurist, was appointed Lecturer on Medical Jurisprudence at Guy's Hospital. His inaugural course was the first delivered in this country, and was attended by many leading counsel and some judges.

\section{Poblic Health.}

In 1842 Parkes was Assistant Surgeon to the 84th Regiment when he retired and became physician to University College Hospital. He was the founder and first teacher of military hygiene, and was a great factor in, if not the founder of, the science of modern hygiene.

The elaborate directions in the Mosaic laws for the pre servation of health, through scrupulous attention to cleanliness and the isolation of the sick and extreme care in the use of wholesome articles of, food and drink, are well known to Biblical students.

The subject has in later years been studied to considerable advantage. In 1801 Heberden wrote: "The cause of so great an alteration in the health of the people of England-for it is not confined to the metropolis-I have no hesitation in attributing to the improvements which have gradually taken place, not only in London but in all the great towns, and in the manner of living throughout the kingdom, particularly in respect to cleanliness and ventilation. Two centuries ago the mortality of London is stated to have been 80 per 1,000 at the present day it is under 20. A century ago ships could barely keep the sea for scurvy, whilst gaols and hospitals were in many cases the hotbeds of fatal disease. Now these conditions are rectified, or at least the means of rectifying them are known."

The special departments which concern the surroundings of man-his personal health, food, drink, clothing, hours of labour, and certain other points, such as the management of infancy, the prevention of disease, the hygiene of the sick chamber, and the disposal of the dead-have been the subjects of legislation during the present century.

State medicine, as an organised department of administration, is entirely of modern growth. The first Act in this direction was the Towns Improvement Act of 1847 ; but it was not until the following year, 1848 , that a general Public Health Act, embracing the whole of England (except the metropolis), was passed.

The Local Government Board was created in 1871 , and finally in 1875 the existing laws were digested into the Public Health Act, of 1875 ( 38 and 39 Vict.).

These Acts were the result of the labour and agitations of many sanitary reformers and associations, such as the Health of Towns Association, the British Association for Improving the Dwellings of the Industrial Classes, which built the first model dwellings.

Such are some of the incidents of the past that have helped to make us what we are. I am deeply sensible of the imperfect and fragmentary sketches I have recorded, but they show, I hope, a record of progress in the physician of to-day in education, in social status, and in all that goes to make professional life more pleasant. Questions are constantly arising affecting the interests of the profession, and many at this moment require combined as well as personal action. It is the consideration of these matters, in addition to our scientific work, which justifies the existence of the British Medical Association.
Exphenses of Modern Medical EddCation.

In conclusion, may I briefly refer to the growing expense of medical education? It is certainly the most costly of all the learned professions. This is due to the long period of time required for the medical curriculum, and to the multiplication of qualifications, which I regard as a fashionable absurdity. I am not unmindful of the up-to-date requirements of general culture-of an accurate knowledge of anatomy, chemistry, physiology, biology, bacteriology, pathology, physics, optics, mechanics, electricity, and photography, which are all essential to the well-educated physician they are daily called into requisition in order to diagnose and to direct the eye and hand in the treatment of disease. The necessity for the highest education for this mental training is obvious, and it rests with the General Medical Conncil to see that this can be obtained without undue restrictions. What I venture to think is wanted is early qualification, and if the elements of science were more generally taught in school life that would be easily possible. After obtaining a diploma or licence to practise it would be well if the General Medical Council could see their way to institute the requirement of practical experience.

In passing the milestone of life in the year A.D. I900 I have thought it might be well to take a retrospect of our advance to our present position, and to express the hope that as time goes on our profession may continue to uphold its regard in the estimation and affection of all, and its usefulness may continue unchecked for the advantage of humanity.

[I am indebted to the following books (as I have consulted them at large I have not in many instances given detailed references): Green's History of the English People, Lecky's History of England, Encyclopoedia Britannica, Dictionary of Nutional Biography, Short Bistory of Natural Science (Buckley), Masters of Medicine, Chambers's Biographical Dictionary, and other classical authorities.]

\section{ADDRESS IN MEDICINE}

BY

\section{PHILIP H. PYE-SMITH, M.D., F.R.C.P., Consulting Physician to Guy's Hospital.}

At the Annual Meeting of the British Medical Association at Ipswich, July-August, 1900.

\section{MEDICINE AS A SCIENCE AND MEDICINE AS AN} ART.

Mr. President and Gentlemen,-It has sometimes been disputed whether medicine should be regarded as a science or an art; but there is no doubt that the original meaning of medicine, and of the corresponding terms in other languages, is the art of healing. Medicine is so defined by Aristotle, and the art of curing, to which we may add the art of preventing disease, has all the characters of an art. It depends upon experience and skill ; it deals with individual cases; and the perfection it aims at is practical, not speculative-the knowledge how to do something, not the knowledge how things happen. Nevertheless, as practical navigation is founded on astronomy, meteorology, and physics ; as the art of agriculture rests on botany, geology, and vegetable physiology, so the art of medicine depends on the science of pathology, the practice of physic on the principles of physic.

On the one hand, then, we must never forget that we practise an art; we must never allow theories, or even what appears to be logical deduction, or explanations however ingenious, or statistics however apparently conclusive, or authority however venerable, to take the place of the only safe rule of practical medicine-observation and experience. We must never treat the disease without considering the patient, for the art of healing is the art of healing individually. Nor need we wonder if vast knowledge, profound learning, and the best scientific training sometimes fail to make a successful practitioner; for beside adequate knowledge, to save us from gross blunders, and a strenuous endeavour to do our best for each individual patient, however uninteresting the case or however irksome and thankless our toil; beside 
these first requisites for our art, there is ample room for those personal qualities which ensure success in every departmen of life-power of observation and insight, the personal influence by which a strong character will secure obedience and inspire hope, the judgment which divines what kind of remedies are suited to each patient, what kind and of what strength, and the sympathy which puts one in the patient's place, and not only meets, but anticipates, his wants.

If, however, medical science without art is inefficient medical art without science is not only unprogressive, but almost inevitably becomes quackery. As soon as we treat our patients by rule of thumb, by tradition, by dogmas, or by metaphysical axioms, we do injury to ourselves as well as to them. The bonesetter who is ignorant of anatomy, the wise woman who cures by charms, are not more irrational or less successful than was the physician of the seventeenth century who, in obedience to the doctrine of signatures, advised an in fusion of roses for hæmorrhage, and saffron for jaundice, and lung-wort for consumption; or the astrologer who prescribed salts of silver, iron, lead, or mercury in accordance with the horoscope of the patient and the planet under which he was born. Not less mischievous, and in the true sense of the word unscientific, were the systems of medicine known as the iatro-mechanical and the iatro-chemical, which in their turn had their vogue. The Brunonian system, explaining all diseases as due to laxity of fibre, was no better; for indiscriminate use of "corroborants," or, as they would now be called, tonics, is as irrational as that of hydropathy, of alcoholic stimulation, or of electricity. There is no such thing as a tonic or strengthening medicine: the sole source of strength is oxydisable food, and bitter medicines can only give strength by improving the appetite. The last of the systems of medicine founded on a dogma is homcopathy, of which the theoretical absurdity is somewhat concealed by the more obvious nonsense of infinitesimal doses. It, like the other systems which preceded it, is not a rival to rational medicine; they are not mistaken answers to a legitimate question, but attempted solutions of a problem which does not exist, attempted answers to a riddle which has none.

Apart from these exploded systems of treatment, our profession has often suffered from lack of the scientific, inquiring, sceptical spirit, and has often been led too easily by authority, by tradition, and by fashion. The reckless abuse of venesection in the last century and the former half of this led to almost complete disuse of a valuable means of treatment; the misuse of mercury in the treatment of syphilis led to denial of its unquestionable efficacy. Have we not seen the value of stimulants in a contest with fever lead to their indiscriminate use in almost every ailment? Has not the immense value of careful and thorough nursing sometimes ended in its exaltation to an independent place, as if good nursing was anything more than an intelligent carryingout of the physician's directions? Have not the remarkable powers of electrical stimull led to a blind, unscientific, and mischievous employment of this remedy, as if it had some mystic efficacy apart from its demonstrable physiological effects? May we not say the same of hydropathy, of massage, and of hypnotism?

It is significant that the irrational exaltation of any of these particular modes of treatment into a panacea, while it begins in want of scientific intelligence invariably ends in imposture and deceit. Our only safeguard against the spirit of quackery and the deserved loss of public confidence in the profession which it brings with it is continued recurrence to the scientific basis on which the practice of medicine rests. Our art is most satisfactory and efficlent when most closely resting on science. The surgeon is continually guided by anatomy and mechanics in dealing with injuries or deformities. The physician is often able to apply his knowledge of chemistry and natural history to the direct and satisfactory treatment of disease. Generally, we can appeal to the same test as that which proves astronomy or chemistry to be a true science; we can predict and our predictions are borne out by the event. But to take examples, the detection and treatment of plumbism, the diagnosis and cure of scabies and ringworm, the treatment of poisons by chemical antidotes, and of specific diseases by attenuated inoculstions are all instances of strictly scientific medicine. Nor can I refrain from citing the most recent and one of the most remarkable.advances of our science in the discovery of the origin of malaria. This beavy tax upon national as well as individual vigour and happiness has been known and treated from the dawn of medicine; but although by a happy accident its efficient treatment was discovered, it is only lately that by the combined labours of scientific physicians, Frenchmen, Italians, and our own countrymen, that the origin of the disease has been discovered, the mode of its transmission traced, and the diagnosis of its several forms established.

We know that treatment of symptoms without a diagnosis is always unsatisfactory and frequently worse; but we know also that diagnosis must rest upon accurate knowledge of morbid anatomy and of the natural history of the disease. Scientific medicine based on observation and experiment is always practical as well; but empirical medicine, whether based upon fanciful speculation or working by rule of thumb. is the most unpractical thing that can be.

Etrology and Preventive Mredicine.

That important and constantly growing branch of medicine, which deals with the prevention rather than the cure of disease, depends no less upon science, for tracking the dependence of one event upon another is the essence of inductive science. All efficient measures for the preservation of health, whether by individuals or communities, rest upon exact knowledge of the natural course of diseases. In fact, disease may be defined as the reaction of the human organism under conditions which make for its destruction. We must never forget that no irritant will cause inflammation in a lifeless skin; that no bacteria can produce fever without a nervous system to play upon; that no meal, however Gargantuan, and no potations, however deep, can produce their wonted effect without a stomach to react. The infection of small-pox, of diphtheria, or of tubercle exerts a very different influence upon vaccinated or unvaccinated subjects, upon one who has received and one who has not received the prophylactic serum, upon an organism which is predisposed to or refractory against the invasion of the enemy.

How closely natural science is related to preventive medicine is shown by the history of Jenner, who was a naturalist, and Pasteur, who was a chemist. How dependent we are upon science is well illustrated by the history of myxœdema. The cretinoid condition in adults which was discovered by the clinical acumen of Sir William Gull, unintentionally produced by the surgical skill of Professor Kocher, and reproduced in animals by Mr. Horsley, is now cured by the eminently scientific method due to Dr. Murray of Newcastle, and to Dr. Hector Mackenzie of St. Thomas's Hospital.

Such examples of accurate tracing of causation by observation and experiment admonish us to give up the perfunctory explanations which so often do duty for investigation. If we ascribe every inflammation to cold, and every doubtful symptom to gout; if we acquiesce in the popular ascription of disease to overwork, mental strain, and the nervous tension of modern life, we shall make no progress in true etiology. I see many patients suffering from idleness, few, or none, from hard work. "Nerve prostration" from "worry" and "brain tension"generally proves to be a decent veil to the effects of gambling and drink. Contrary to popular belief, I hold that modern life is easier, safer, and smoother than it was a hundred years ago, that our young men and maidens are healthier, stronger, better grown, less emotional, less hysterical, and sounder in mind and body than their greatgrandparents; and I hold that the duty of a physician is not to flatter the selfishness of neurotic patients, but to inspire fortitude, and to prescribe regular and steady work, as the best cure for a thousand nervous ailments.

As another point in scientific etiology, allow me to warn against the temptation to assume that because many diseases are now proved to depend upon the presence of bacteria, this must be true of all. Science does not anticipate but. waits for proof. We have complete scientific evidence, according to the criteria so well formulated by Koch, of the absolute and constant cause of anthrax, of relapsing fever, of tubercle, and of several other diseases in both men and animals ; but we must not forget the preliminary difficulty of identifying the specific bacillus, as in the case of enteric fever and diphtheria; nor the difficulty of finding one of the lower animals which is susceptible to the disease, as again in the case of typhoid fever and of cholera; nor the difficulty of the 
same anatomical and clinical conditions being produced by different organisms, as is the case with pneumonia and ulcerative endocarditis. Moreover, while in some diseases, which are undoubtedly infective and specific, no constant pathogenic microbe has yet been determined, as in typhus, measles, small-pox, and syphilis; we have on the other hand in the case of leprosy and of lupus examples of disease unquestionably specific and bacterial in origin, but very unlike other infective maladies in clinical course and natural history. At present it is surely undesirable to speak of "the undiscovered microbe of rheumatism." Science has to do with proved facts, and our language should never outrun our knowledge.

Prognosis and Statistics.

Another important branch of medicine-prognosis-depends as an art upon experience and insight. In making an individual prognosis, shrewd powers of observations are needful ; and in this, of all branches of our art, it is true that:

old experience doth attain

To something like prophetic strain.

Yet here also rational prognosis rests on the science of statistics.

It is to Louis and the French school of the second quarter of this century that we owe the application of this important method for learning the natural history of disease, a methnd which not only supplies a foundation for prognosis but alsu a criterion of treatment. We know, however, how many pitfalls there are in deducing conclusions from statistics. The morbidity or incidence of a particular disease upon the whole community is often confused with the mortality or the fatal cases of it compared with the population, and this last confused again with the case-mortality. The return of death from a certain disease in a town or kingdom has been applied to the population which existed eight or nine years before The success of treatment of a disease occurring in barracks, that is to say, among picked subjects, all in early manhood, under strict discipline, and sent to hospital as soon as they are unwell, has been compared with that of other measures carried out in totally different circumstances. As examples c'statistical misuse take these facts : the numerical return of the lying-in charity of a London hospital led to the conclusion that more women are delivered of a second child than of a first. A physician, to inspire confidence in an anxious patient, assured him that the mortality of the complaint from which he was suffering was only 1 per cent. ; and in answer to the further inquiry whether he had seen many cases, said "Yes; I have looked at my note books and find I have seen 99 and they all recovered."

But, apart from the corrections and limitations of statistical science, we are sometimes in danger of forgetting that to be of any value statistics must be based ucon cases which are both numerous and accurate. A small number of cases is useless. It led to the conclusion that myxœdema was peculiar to women, and that insular sclerosis was rare in men. It was only after hundreds of cases had been observed that we learnt that infantile paralysis sometimes befalls adults, and that osteo-arthritis may occur in children. This defect may be remedied by time, but the defect of inaccuracy is without remedy. If diagnosis is perfunctory or careless and nomenclature arbitrary and inconstant, the more case observed the less do they teach. It is disappointing, after the immense labour, time, and trouble devoted to the compilation of the official Nomenclature of Diseases of the Royal College of Physicians, that, although adopted in the navy and army and by the Registrar-General, it is constantly neglected, not only in conversation but in systematic treatises. How can statistics be anything but misleading when made up of cases of one and the same disease under such different titles as chronic rheumatism, rheumatic gout rheumatoid arthritis, arthritis deformans, and osteo-arthritis Of what value are statistics when such different diseases as acute lobar pneumonia, broncho-pneumonia of children after measles, pulmonary tuberculosis, cirrhosis, and septic suppuration of the lung are all labelled "pneumonia?" One difficulty is put in the way of the practitioner in making an accurate return by the well-meant but, I think in practice, unfortunate provision for returning a primary and a secondary cause of death. Sometimes this corresponds to facts and gets over a difficulty, but if a patient dies of enteric fever there is nothing gained by adding exhaustion as the secondary cause still less do we learn from a return of primary cause a chill, secondary cause debility; or primary cause an accident, secondary cause dropsy. As a matter of fact, in looking through hundreds of death certificates, on arrives at the valuable conclusion that a frequent cause of death is " cardiac failure."

Another and opposite mistake is often made by attempting too great precision in diagnosis. To say that a man died of apoplexy or of paraplegia is to state a fact within any competent practitioner's knowledge, but, in the absence of a postmortem inspection, to say that he died of cerebral hrmorrnage or of myelitis is not a fact, but a more or less doubtful inference. It is surely better to be satisfied with a statement that there was ascites and enlargement of the liver when the cause of enlargement is altogether uncertain, than to be more exact and less true. I have again and again seen disease the existence of which no experienced physician would assert without a necropey returned as if they were common and easily recognised conditions-pernicious anæmia, syringomyelia, cancer of the lung. It would, I venture to submit, be a great improvement if the return of one cause of death only were demanded; if certainty and definite statements were aimed at rather than speculative minuteness or vague generalities; if a query were allowed to qualify deductions as distinct from observations; if the fact of a necropsy were always stated; and, lastly, if the authorised [nomenclature were always used.

Scientific Medicine and Experiments.

There is one aspect of scientific medicine so important that it must not be wholly omitted : the necessity of experiments for the progress of pathology, and through it for the prevention and cure of disease. It requires no argument to convince anyone who is the least acquainted with the principles of inductive science that experiment is no less necessary than ob servation. In physics and in chemistry this is obvious and universally acted on. The same method is indispensable for the progress of animal and vegetable physiology, and to such prastical applications of science as engineering, agriculture, and medicine. Nor can experiments be restricted to rare, occasional, and solemn occasions ; they must be carried on in large numbers by many different experimenters and under every variety of conditions. Any attempt to abolish, to check, or to limit this experimental work is, in the degree that it is successful, fatal to progress. Happily it can never be successful, for the impulse to increased knowledge of the works of creation is too deeply implanted in man. Investigation must and will go on by the only path which it can follow. The method which was preached by Bacon and followed out by his great contemporary William Harvey, which was continued by Lower, Hooke, and Mayow, in the early days of the Royal Society by Aselli, Malpighi, and Haller, by Hunter and Hewson, by Hales, by Edward Jenner, by Sir Charles Bell by Johannes Müller, by Claude Bernard, by Ludwig, and by the many eminent physiologists and pathologists in Germany in France, and throughout the civilised world - this method of investigation must and will continue. As its objects and methods are better understood, it will secure the enlightened patronage of all who desire the improvement of human knowledge and the increase of human happiness. Fortunately this very progress of science has brought with it the removal of the one drawback which every right-thinking man must have felt as a grave disadvantage to these experiments upon living animals. Inflicting pain upon the humblest of God's creatures is repugnant to our feelings, though no one, unless maintaining a thesis, would contend that it would be wrong to exact the most painful efforts, or even the death from exhaustion, of a horse, in order to carry help to a human being. The discovery of ether, chloroform, and other anæsthetics, and the improved methods that we owe to the genius of Lister, have not only relieved the surgeon of the most repulsive part of his duties, but have relieved the experimenter also. Except in the investigation of the action of new remedies or in the inoculation of infective diseases-both of which inflict discomfort of a limited degree and duration rather than anything that can be described as pain-the experiments of the laboratory, whether physiological, pathological, or therapeutical, are conducted without inflicting 
suffering. The opposition to them has not succeeded, and is sure to diminish. However mistaken our opponents, we are glad to find there is exaggerated jealousy to avoid anything approaching to cruelty. This legitimate object our more candid critics may be assured is already amply provided for.

Theraprutics and Science.

Lastly, how far is the final end of our art-the cure of disease-immediately and directly dependent upon science? It rests, we know, on that sure basis; but even in its practical carrying out we are bound to take with us a sclentific spirit. The administration of digitalis for cardiac dropsy, of mercury for syphilis, and of thyroid extract for myxœdema is as truly scientific as prescribing a chemical antidote for poison, or nitroglycerine for angina pectoris, for it rests on a sure basis of observation and experience. But because in many cases we cannot as yet explain how remedies act, we should never prescribe them without watching the effects of the experiment. The foolish cry against hospitals as places where they experiment on patients is meaningless just because it is true. Every prescription we give either to rich or poor is an experiment, and ought to be watched with critical and scientific eyes. And here leti me say that our practice is often ineffectual, not for want of adequate means of treatment, but merely for want of the needful treatment being thoroughly carried out-a want which inevitably prevents success, and therefore leads by a vicious circle to scepticism and the same half-hearted treatment on the next occasion. A man who believes everything he is told of the action of remedies not only in the serious treatises of Garrod or Wood or Binz, but in the partial assertions of advertising druggists, is sure to be unsuccessful ; and, beginning with credulity, is apt to end in unbelief of such remedies as colchicum, salicin, and opium. Such a man will prescribe and will never see that his prescription is carried out; by the habit of giving multifarious mixtures of drugs in ineffectual doses he allows what he has prescribed three times a day for a fortnight to be really taken twice or once a day for a week. He will prescribe exercise or lying down, abstinence or feeding, and never trouble himself to see that his directions are carried out. Who shall blame the patient if he ceases to believe in remedies to which the physician obviously attaches no importance? If we would sometimes prescribe no drug at all, but insist on abstinence from certain articles of food or drink, upon more frequent or less frequent meals, upon regular exercise or absolute rest, should we not secure more obedience from our patients when we prescribed really necessary drugs-just as a clergyman who desires to get a libera collection would do wisely to begin ky insisting on the sin of giving to charities which one believes to do more harm than good? How can we expect success in treating an obscure nervous affection if we apply galvanism to the spine without making sure of any physiological effect, nay, sometimes without making sure that a current is passing through the electrodes; or if we send a patient to drink the waters of such and such a fashionable watering-place without remembering that there are two or perhaps three springs, one of them inert and the other very possibly injurious? What success can be anticipated if we order ointment for a weeping eczematous patch, where it floats on the secretion and never reaches the inflamed tissue; or if we prescribe a lotion to be applied twice a day to skin well protected by its sebaceous secretion? We all know this half-hearted, ineffectual mode of action in everyday life; the man who wipes his shoes as a ceremony and never looks to see if he had got rid of the mud; the groom who feeds his horse but never sees whether the oats are eaten; the nurse who washes the child and still leaves wet places. Now much of this weak and therefore useless treatment is only the indolence to which we are all prone, and against which we must struggle as a temptation : but much of it, I am sure, is the offspring of incredulity, and this again springs from half belief in quackery and imposture. Much of our ineffectual treatment again depends upon want of belief in our diagnosis. Until we make up our minds whether a certain eruption is psoriasis or a scaly syphilide, we shall never deal with it successfully. If we only suspect syphilis, we shall give our remedies in inadequate doses, and relinquish them if we do not see immediate benefit; whereas if our diagnosis is real and thorough, we shall use our remedies with confidence, increasing the doses, varying the form, but always persevering until we obtain their physiological effect-then we may reasonably hope to cure our patient.

Another source of failure in therapentics is the legion of new remedies, the eulogium of which fills our waste-paper baskets and lights our fires. It is astonishing to find apparently rational men forsaking the drugs which have been proved effectual by the experience of long-past time and of all civilised nations to take up with remedies the composition of which is often unknown, the use of which they have never learned, and of which the value rests upon the interested or credulous assertions of those who try to sell them. It takesa. man long years of practice to learn how to prescribe opium. Why throw away this priceless knowledge to dabble in quack cures of which the very praises inspire distrust? New remedies are no doubt discovered from time to time-in this generation we have had several-and all probable claimants should be tested in pharmacological laboratories and in hospital wards. But I am speaking of drugs which have never passed either of these tests. Surely in this age of advertisements which disfigure and defile the beauties of land and sea, of town and country, of literature and art, the most credulous must be convinced that costly and pertinacious advertisement is evidence of the lack, rather than the possession, of genuine worth. No, sir, so far from our profession being carried away by this noxious habit, let us hope that we may not only stamp it out from among ourselves, but spread our own standard of conduct to other pursuits, until some day an honest tradesman shall be ashamed to push his sales by self-laudation and the wealthy manufacturer shrink from offending the eyes and deafening the ears of his fellowcreatures by scribbling his name on blank walls and screaming it in every street.

In another popular branch of treatment it seems very desirable that the scientific spirit should be somewhat more freely admitted-I refer to treatment by baths and waters. That both are valuable modes of treatment no one will deny, but who will be so bold as to assert that it makes any difference whether patients take a bath of water heated as it comes from the soil or heated to the same degree in a kettle?. Who. will pretend that so many grains of laxative or alkaline salts will act differently when occurring in natural solution and when dissolved in the same proportion in the druggist's shop? That benefit is obtained by change of air and scene, by early hours, regulated rest and exercise, and copious draughts of water is beyond dispute; but it is surely a pity when, instead of rational explanation of a "cure," we suffer our patients to be deceived by unscientific and more or less untruthful statements.

Is it not a mistake for so many of us to prescribe the madeup drugs offered us by wholesale manufacturers instead of our own combinations? It leads our patients to ascribe their recovery not to our skill, but to this or that pill or tablet. It would be an excellent task for this great Association to set some of our skilled analytical chemists to strip the veil from mysterious remedies and tell us the exact composition of the many patent medicines, some of which are inert and some injurious.

Rational Medicine and its Wages.

Do we ask whether scientific medicine obtains the recognition that is due at the hands of the public? I believe that on the whole it does, or if in any degree it fails, that the failure is due to ourselves. We cannot expect that any but the most educated and enlightened should look at our science or our art from a rational point of view. The popular notion of a doctor among out-patients is a man who has got some wonderful cure in a bottle, which will make them well. The more educated patients suppose that, knowing what is the matter with them, or as we say, having made their diagnosis for themselves, their next business is to choose the doctor who has devoted his exclusive attention to the malady of which they suppose they are the subjects, or if they chance to suffer from what they call a complication of diseases they will consult a heart-specialist to cure palpitation, a throat-doctor to cure hoarseness, and a rising young surgeon to "a specia) hospital for diseases of the knee," to cure weakness in that joint. If they should find no relief after these consultations 
-Flectere si nequeo superos, Acheronta movebo-they denounce legitimate medicine as useless and go to the lowest impostor, and will afterwards tell their friends that after being " given up by the faculty "they found instant and miraculous relief in a single box of wind-pills, a galvanic belt, or a pad of " oriental herbs" worn on the pit of the stomach.

The fact is that we cannot expect our patients should understand the scientific basis of medicine, the meaning of etiology, or the possible degree of efficiency of treatment. What they frequently ask of us is to allow them to continue the very course of life to which we have laboriously traced their symptoms, and to give them some medicine which, as if by a charm, will break the inevitable sequence of cause and effect. They are slow to understand that this world gives nothing for nothing, and that we can only subdue Nature by obeying her laws.

There is, in fact, but one way in which we can obtain what we call our just recognition. Our services, however great, are services to the individual, not to the community. It is therefore absurd for us to expect the honorific or the more solid rewards justly assigned to statesmen, to generals, or to judges; but from individuals we may expect-and I venture to 8 ay that as a rule we receive-the trust, the honour, and the gratitude which we have earned. Few of our patients will ever understand our principles or our methods, the reason for our successes, or the explanation of our failures; what they do understand is personal character, honesty and sense, kindness and sympathy, liberality and benevolence to rich and poor. These are the qualities which have always gained and still gain the respect of our fellow-men; and I venture to say there is not a town in the three kingdoms where such respect is not widely and deservedly earned by our profession. In every cathedral, in almost every parish church, we see tablets bearing witness to the esteem in which the local practitioner lived and died. He spent his life in the constant exercise of his best faculties, intellectual and benevolent-a sure path to happiness; every day brought fresh interest and left no time for melancholy; he earned not only money but money's worth, in respect and influence; and when the practitioner became the patient-as we all must one day be-he had pleasant memories of a life spent in the service of God and man, and he still lives in the hearts of his grateful patients.

And there sepulcred in such pomp doth lie

That kings for such a tomb might wish to die

Itratian Laryngologican Socikty.-The Italian Society of Laryngology, Otology, and Rhinology held its tifth Congress at Naples, contemporaneously with the Tuberculosis Congress, under the presidency of Professor Masini. Among the communications presented were reports on tuberculosis of the regions of the body with which the Society specially concerns itself. Professor Massei dealt with the disease as it affects the upper respiratory passages, and Professor Gradenigo with tuberculosis of the ear. The morbid anatomy and bacteriology of such cases were discussed by Professor Martuscelli ; Dr. Cozzolino treated of sanatoria in relation to laryngeal phthisis, and Drs. Ferreri and Rosati submitted suggestions for prophylaxis. Professor De Ross reported the results of his investigations as to the testing of the hearing in railway servants, and a resolution was passed approving the step taken by the Sicilian Company in having the hearing of the men in their employ regularly tested, and expressing the wish that its example might be followed by the other railway companies of Italy.

an InTERnational SPIRITUALIST Congress - Like the rest of the world the Spiritualists are taking advantage of the Paris Exhibition to hold an international congress. Their Congress comprises five sections : Spiritual, Magnetic, Hermetic, Theosophic, and Individual Spiritualism. In the Magnetic Section such questions will be discussed as the impropriety of classing human magnetism with hypnotism human magnetism, magnetic procedures, passing of the hands, etc, action of the eyes and of the look; healing mediums, the rôle of suggestion; application of massage in acute or chronic affections; the appreciation of magnetism and massage in different countries; the facilities or obstacles which they met with in different countries; the divining rod; the exterioration of sensibility, etc.

\section{ADDRESS IN SURGERY}

\section{FREDERICK TREVES, F.R.C.S.,}

Surgeon-Extraordinary to H.M. the Queen

Surgeon-in-Ordinary to H.R.H. the Duke of York; Consulting Surgeon to the London Hospital.

At the Annual Meeting of the British Medical Association at Ipswich, August, 1900.

THE SURGEON IN THE NINETEENTH CENTURY.

Mr. President, Ladies and Gentlemen,-The honour of being selected to address an association which represents not only in numbers but also in dignity and repute the medical profession of this country is an honour of such a kind that I feel it can only be belittled by any expressions of gratitude I am able to command. I will do no more therefore than sincerely thank you for bestowing upon me a great distinction, and at the same time remind myself of the words of Goethe that "it is easier to bind $a$ wreath than to find a head worthy to wear it"

I am fortunate also in the circumstance that the occasion for the giving of this address should coincide with the concluding year of the nineteenth century. This century has been without a parallel in the history of human culture, and so far as the art of surgery is concerned has embodied an advance in principle and in practice which has been no other than revolutionary. I do not propose to attempt a review of the progress of surgery during the last hundred years. That work has been already done by abler hands. I would venture rather to deal with the progress of the surgeon himself during this period, and with the advancement of the individual as an exponent of a grave profession.

There is little difficulty in fashioning a picture of England as it was one hundred years ago. A sympathetic literature has left us with ample records of the men and women of the time and of the scenes they moved among. These records are rich with the littleness of personal affairs and are made living by the very gossip and petty commentaries of those who constituted society when the century was young. The life in England then was largely life spent in the country, in sleepy villages, and in sober self-esteeming county towns. The conditions were yet immature which led men to herd together in ever-extending cities and to swarm around oases of blackened chimneys and restless furnaces.

Travelling was a luxury limited to the few. The many were content to live and die within sight of fields and spires which had been familiar from babyhood. They were apparently content to keep to their own stations in life, to take their notions of dignity from the squire and their conceptions of religion from the vicar, and to be satisfied with such excitement as was afforded by harvests and market days, by the movements of the locally great and by the achievements and misdoings of their neighbours. In many a town it was no little event when the coach from London lumbered through the cobbled streets or when a gang of pressed men marched by on their way to the sea or when some soldier home from the wars made the little ale house lurid with tales of arms and tragic lands. These simple folk were comparatively free from the fever of social ambition, from the almost savage conflict of modern commerce, and from the bewildering hurry of events which compass the peace of later times.

London was then not one-fourth of its present size'; the great city ended, towards the west, at Sloane Street and beyond were quiet field and meadows intersected by footpaths, certain of which led to the hamlet of Kensington and the little riverside village of Chelsea. The lover of solitude would have found seclusion in the wide open country through which ran the Edgware Road. Paddington was still in the fields. Game could be shot about Westbourne Green and around the isolated farm house which marked the present settlement of St. John's Wood. Few would have cared to venture after dark across the bare fields of Battersea or to traverse the expanse of open land which stretched to the north of Tottenham Court.

No railway terminus flaunted its hideous structure in the city's midst, and neither omnibus nor cab nor tram car invaded the narrow streets. There was no telegraph and no 